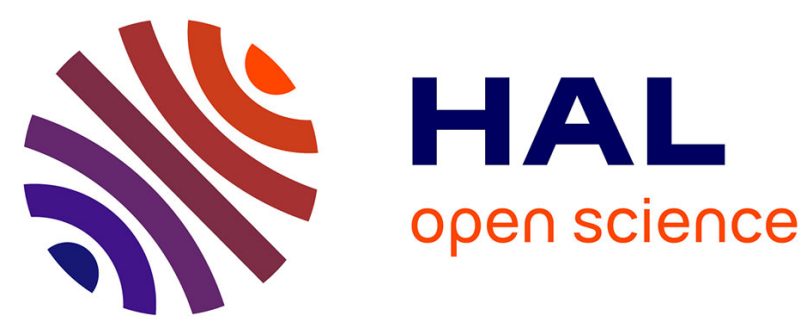

\title{
Combined NMR and X-ray diffraction study of structural aspects, dynamics and charge ordering mechanism in LixVOPO4.2H2O intercalation compounds
}

R Boulé, C Kouvatas, Claire Roiland, T Bataille, V Alonzo, E Le Fur, L Le Pollès

\section{To cite this version:}

R Boulé, C Kouvatas, Claire Roiland, T Bataille, V Alonzo, et al.. Combined NMR and X-ray diffraction study of structural aspects, dynamics and charge ordering mechanism in LixVOPO4.2H2O intercalation compounds. Solid State Nuclear Magnetic Resonance, 2019, 104, pp.101623. 10.1016/j.ssnmr.2019.101623 . hal-02364860

HAL Id: hal-02364860

https://hal-univ-rennes1.archives-ouvertes.fr/hal-02364860

Submitted on 9 Dec 2019

HAL is a multi-disciplinary open access archive for the deposit and dissemination of scientific research documents, whether they are published or not. The documents may come from teaching and research institutions in France or abroad, or from public or private research centers.
L'archive ouverte pluridisciplinaire HAL, est destinée au dépôt et à la diffusion de documents scientifiques de niveau recherche, publiés ou non, émanant des établissements d'enseignement et de recherche français ou étrangers, des laboratoires publics ou privés. 


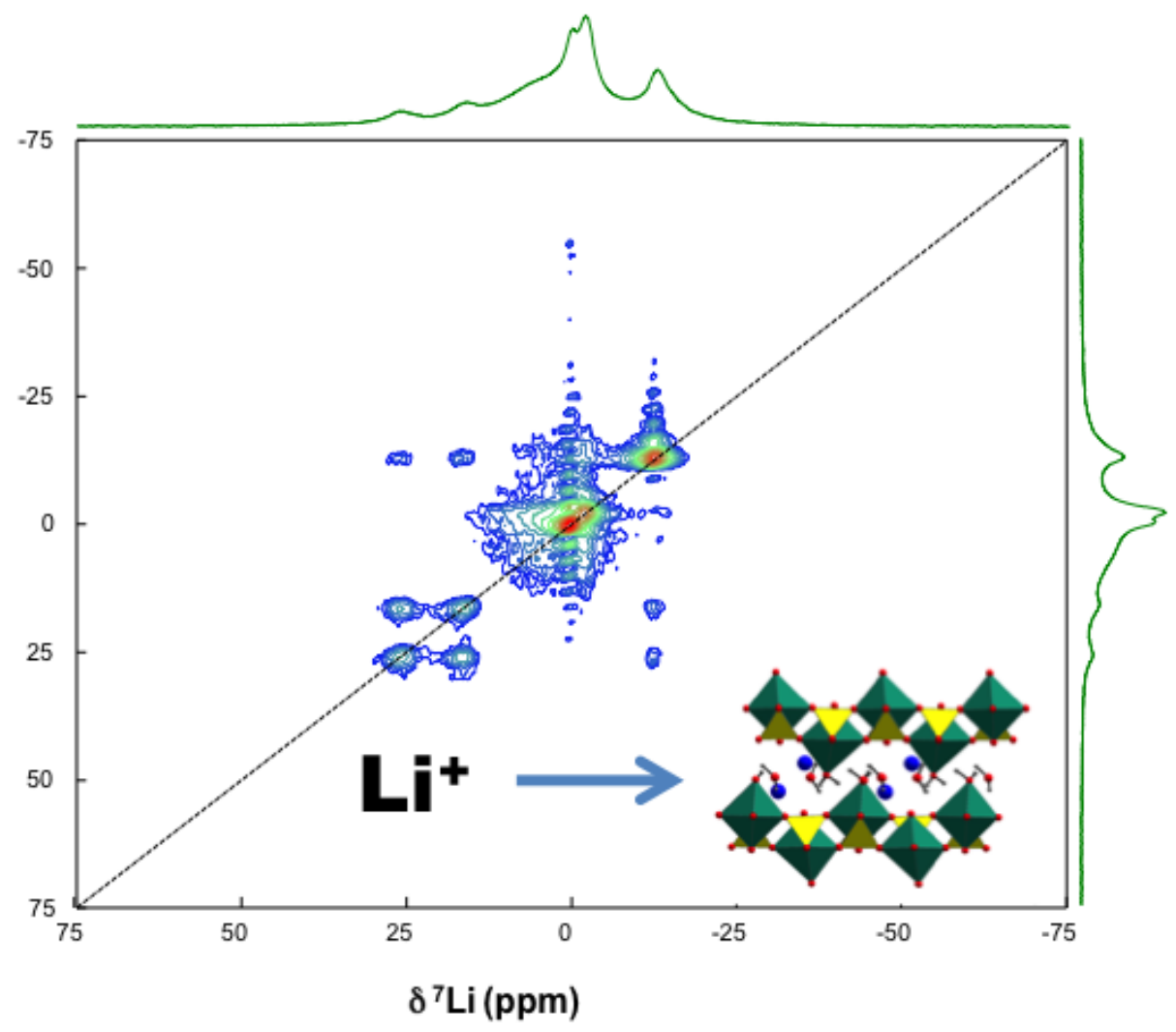


Combined NMR and X-ray diffraction study of structural aspects, dynamics and charge ordering mechanism in $\mathrm{Li}_{\mathrm{x}} \mathrm{VOPO}_{4} \cdot 2 \mathrm{H}_{2} \mathrm{O}$ intercalation compounds

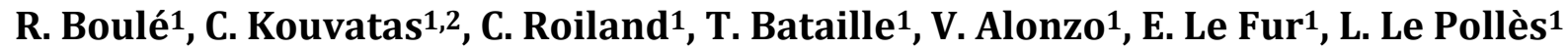 \\ ${ }^{1}$ Université de Rennes, Ecole Nationale Supérieure de Chimie de Rennes, CNRS, ISCR - \\ UMR 6226, F- 35000 Rennes, France \\ 2 Present address: Laboratoire Catalyse et Spectrochimie, Normandie Univ, ENSICAEN, \\ UNICAEN, CNRS, 6 Marechal Juin, 14050 Caen, France
}

This article is dedicated to the memory of Professor Jean-Yves PIVAN, Ecole Nationale Supérieure de Chimie de Rennes (1955-2018)

\begin{abstract}
We carried out a detailed investigation of the local ordering and dynamics of the lithium intercalation in paramagnetic $\mathrm{Li}_{\mathrm{x}} \mathrm{VOPO}_{4} \cdot 2 \mathrm{H}_{2} \mathrm{O}$ (with $0<\mathrm{x} \leq 1$ ) materials.

This question was addressed using a combination of X-ray diffraction, ${ }^{31} \mathrm{P}$ and ${ }^{7} \mathrm{Li} \mathrm{MAS}$ NMR experiments. We first studied the structure of the fully ordered end-member of the series, $\mathrm{Li}_{1} \mathrm{VOPO}_{4} .2 \mathrm{H}_{2} \mathrm{O}$, revisiting the X-ray single crystal diffraction data on the basis of the information provided by ${ }^{31} \mathrm{P}$ MAS NMR. We then carried out ${ }^{7} \mathrm{Li}$ MAS and exchange NMR experiments and ${ }^{31} \mathrm{P}$ MAS experiments on the polycrystalline powders obtained after partial lithium insertion in $\mathrm{VOPO}_{4} \cdot 2 \mathrm{H}_{2} \mathrm{O}$ phases. These experiments evidenced an unexpected ageing of the material related with lithium dynamics between the $\mathrm{VOPO}_{4}$ layers and $\mathrm{V}^{4+} / \mathrm{V}^{5+}$ charge ordering mechanism within the layers.
\end{abstract}

Keywords : Intercalation compounds, ${ }^{7} \mathrm{Li}$ and ${ }^{31} \mathrm{P}$ MAS NMR, local ordering, dynamics, ${ }^{7}$ Li EXSY NMR, X-ray diffraction

\title{
Introduction
}

Vanadium phosphate-based compounds are the subject of abundant work due to their very interesting properties and potential or actual application in various fields of chemistry. The vanadyl pyrophosphate along with $\mathrm{VOPO}_{4}$ polymorphs [1] are used as catalysts for the redox conversion of butane into maleic anhydride. The numerous oxidation states accessible for vanadium (from +2 to +5 ) and its electrochemical activity makes it of great interest in energy storage as positive electrode for lithium batteries. Compounds like $\mathrm{LiVOPO}_{4}, \mathrm{LiVPO}_{4} \mathrm{~F}$ and $\mathrm{Li}_{3} \mathrm{~V}_{2}\left(\mathrm{PO}_{4}\right)_{3}$ are among the most studied in this field [2-4]. More recently vanadyl phosphate layers have been assembled to graphene nanosheets to build up supercapacitors composite materials [5].

In the intercalation chemistry $\mathrm{VOPO}_{4} \cdot 2 \mathrm{H}_{2} \mathrm{O}$ has been intensively studied [ 6 and ref. therein]. It has been first synthetized by Ladwig in 1965 [7] and its layered structure, in which neutral $\mathrm{VOPO}_{4} \cdot \mathrm{H}_{2} \mathrm{O}$ layers are separated by water molecules, was determined by Tieztze [8]. This structure is well known for its intercalation properties. Neutral species like organic molecules (alcohols, amines, ...) and cationic species can be readily inserted between the inorganic sheets. The cation insertion occurs along with the reduction of vanadium cations leading to negatively charged layers. Pioneering works in the intercalation of alkaline cations have been carried out by Jacobson et al. $[9,10]$. The 
lithium intercalation has been revisited by several groups[11]. Recently, a structural description of $\mathrm{LiVOPO}_{4} .2 \mathrm{H}_{2} \mathrm{O}$ has been published [12] since it forms one of the precursors of various $\mathrm{LiVOPO}_{4}$ polymorphs [13].

Most of the time, the structure determination of such 2D materials remains elusive. In effect, stacking faults, random distribution of intercalated species, and layer distortion impede a sufficient level of crystallisation. This was for example observed in the dehydration-rehydration process in $\mathrm{VOPO}_{4} \cdot 2 \mathrm{H}_{2} \mathrm{O}$. Upon partial dehydration multiple stacking faults appear [14], while its rehydration occurs with a probable random distribution of water molecules within the layers, which creates diffraction line broadening. [15] At room temperature, ${ }^{2} \mathrm{H}$ NMR experiments performed on $\mathrm{VOPO}_{4} \cdot 2 \mathrm{H}_{2} \mathrm{O}$ proved the existence of sub-microsecond dynamics related to the motion of the water molecules and a two-dimensional diffusion of the interlayer species has been proposed. [16]

In this work, we employed ${ }^{31} \mathrm{P}$ and ${ }^{7} \mathrm{Li} \mathrm{NMR}$ combined with X-ray diffraction in order to characterize the local ordering and the dynamics of lithium intercalation within the $\mathrm{VOPO}_{4}$ layers. The lithium intercalation in the $\mathrm{Li}_{\mathrm{x}} \mathrm{VOPO}_{4} \cdot 2 \mathrm{H}_{2} \mathrm{O}$ (with $0<\mathrm{x} \leq 1$ ) materials leads to paramagnetic compounds and the NMR techniques must be adapted to this particular case.

We first synthesized the end member of the series: lithium vanadium phosphate $\mathrm{LiVOPO}_{4} \cdot 2 \mathrm{H}_{2} \mathrm{O}$ by a conventional hydrothermal route, which led to single crystals and allowed us to perform a re-determination of this fully ordered structure.

Smaller amounts of lithium could be chemically incorporated in microcrystalline $\mathrm{VOPO}_{4} \cdot 2 \mathrm{H}_{2} \mathrm{O}$ powders. The local ordering and dynamics of the lithium ions within the layers were studied by exchange NMR experiments and allowed the charge ordering mechanism, which takes place on an unexpectedly long timescale, to be described.

\section{Experimental details}

- Synthesis

Hydrothermal synthesis of $\mathrm{Li}_{1} \mathrm{VOPO}_{4} \cdot 2 \mathrm{H}_{2} \mathrm{O}$ :

A mixture of $\mathrm{V}_{2} \mathrm{O}_{5}\left(0.262 \mathrm{~g}\right.$ ), $\mathrm{LiH}_{2} \mathrm{PO}_{4}\left(1.676 \mathrm{~g}\right.$ ), $\mathrm{H}_{2} \mathrm{C}_{2} \mathrm{O}_{4}(0.262 \mathrm{~g}$ ) (purchased from Aldrich) and water (5 mL) was introduced to a Teflon acid digestion bomb (23 $\mathrm{mL}$, Parr Instruments) and heated at $120{ }^{\circ} \mathrm{C}$ for 4 days. After slowly being cooled to room temperature $\left(0.1{ }^{\circ} \mathrm{C} / \mathrm{min}\right)$, blue crystals were recovered by vacuum filtration, washed with water, and dried in a desiccator. A $81 \%$ yield (based on vanadium) was obtained for $\mathrm{LiVOPO}_{4} .2 \mathrm{H}_{2} \mathrm{O}$.

Synthesis of VOPO $4.2 \mathrm{H}_{2} \underline{\mathrm{O}}$ :

VOPO ${ }_{4} .2 \mathrm{H}_{2} \mathrm{O}$ is the precursor of $\mathrm{Li}_{\mathrm{x}} \mathrm{VOPO}_{4} \cdot 2 \mathrm{H}_{2} \mathrm{O}(0<\mathrm{x}<1)$ and was synthesized by reflux. A quantity of $\mathrm{V}_{2} \mathrm{O}_{5}(16.5 \mathrm{mmol}, 3.008 \mathrm{~g}$, Aldrich, purity $>98 \%)$ was introduced in a two-neck round-bottom flask with phosphoric acid 85\% (430 mmol, 25mL, Sigma-Aldrich, purity >99\%), nitric acid 65\% (1 $064 \mathrm{mmol}, 75 \mathrm{~mL}$, Sigma-Aldrich, purity $>99 \%)$ and deionized water $(75 \mathrm{~mL})$. The reflux was maintained during $3 \mathrm{~h}$, followed by slow cooling to room temperature. The 
solvent was removed by suction and the bright yellow solid was rinsed with water and acetone and finally dried in a desiccator for several days.

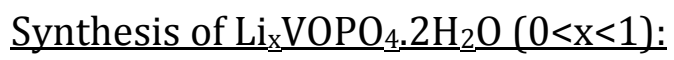

The dark green compounds were obtained by introducing to beakers the precursor $\mathrm{VOPO}_{4} .2 \mathrm{H}_{2} \mathrm{O}(2.5 \mathrm{mmol}, 0.5 \mathrm{~g})$ and lithium iodide $(0.73$ to $3.59 \mathrm{mmol}$, 0.0972 to $0.481 \mathrm{~g}$, Aldrich, purity $98 \%$ ) with $20 \mathrm{~mL}$ of acetone. The mixtures were stirred during $72 \mathrm{~h}$ and then the solvent was removed by suction and the solid was rinsed with water. Sample were stored in a desiccator under air atmosphere during the ageing process.

\section{- X-ray diffraction}

Single crystal data collection

A blue prismatic single crystal of $\mathrm{Li}_{1} \mathrm{VOPO}_{4} \cdot 2 \mathrm{H}_{2} \mathrm{O}$ with approximate dimensions $0.24 \times$ $0.10 \times 0.036 \mathrm{~mm}^{3}$ was selected under an optical microscope and mounted on a glass fiber. Diffraction data were collected at room temperature on a four-circle Nonius Kappa CCD diffractometer using the graphite monochromated Mo K $\alpha$ radiation $(\lambda=0.71073 \AA)$. The intensity data collection was performed through the program COLLECT [17]. The compound structure was solved by the direct methods (SIR 97 [18]) and refined by the full matrix least-squares procedure based on $\mathrm{F}^{2}$, using the SHELXL [19] computer program belonging to the WINGX software package [20]. All the non-hydrogen atoms were subjected to anisotropic refinement.

\section{Powder Diffraction}

X-ray powder diffraction measurements were acquired at room temperature on a Panalytical Empyrean powder diffractometer $\theta-\theta$ Bragg-Brentano geometry working with the $\mathrm{Cu} K \alpha$ radiation $\left(\lambda K \alpha_{1}=1.5406 \AA, \lambda K \alpha_{2}=1.5444 \AA\right.$ ) selected with a flat multilayer X-ray mirror (Bragg-Brentano $\mathrm{HD}^{\circledR}$ ). Data were collected with a Pixel 1D silicon-strip detector, in the appropriate angular range.

- Thermogravimetric analyses

Thermogravimetric measurements were performed with a TA instruments SDT Q600 thermobalance under air from room temperature to $600^{\circ} \mathrm{C}$ with a heating rate of $5^{\circ} \mathrm{C} / \mathrm{min}$ and an air flow of $50 \mathrm{~mL} / \mathrm{min}$.

- Elemental analysis

The lithium content of the samples was determined by atomic absorption spectrophotometry using a VARIAN SpectrAA 120.

- $\quad$ Solid state NMR

31P solid-state NMR spectra were acquired using a Bruker 300 AVIII spectrometer (7 T) operating at Larmor frequencies of $121.65 \mathrm{MHz}$. Samples were packed into $2.5 \mathrm{~mm}$ outer diameter rotors and rotated at spin rates of $30 \mathrm{kHz}$. Spectra were referenced to aqueous $\mathrm{H}_{3} \mathrm{PO}_{4}$ 
1D ${ }^{7} \mathrm{Li}$ NMR spectra were acquired a pulse length of $2 \mu \mathrm{s}$ with a RF field of $125 \mathrm{kHz}$ for the experiments carried out at $14 \mathrm{~T}$ (Fig.4) and $3.25 \mu$ s with a RF field of $77 \mathrm{kHz}$ for the 7 $\mathrm{T}$ experiments (Fig.5). In both cases a recycle delay of $0.3 \mathrm{~s}$ was employed. The spectra are referenced to $1 \mathrm{M} \mathrm{LiCl}(\mathrm{aq})(0 \mathrm{ppm})$. Most of the ${ }^{7} \mathrm{Li}$ MAS NMR spectra were acquired on a Bruker AV III 300 spectrometer operating at a Larmor frequency of $116.6 \mathrm{MHz}$. The experiments were performed at low field in order to minimize the paramagnetic broadening [21]. A $2.5 \mathrm{~mm}$ double-resonance probe was used with a spinning frequency set to $30 \mathrm{kHz}$.

2D exchange spectra (EXSY) were acquired using a NOESY pulse sequence [22]. ${ }^{7} \mathrm{Li} 2 \mathrm{D}$ EXSY spectra were performed under MAS condition with a spinning rate set to $30 \mathrm{kHz}$. Mixing times between $0.5 \mathrm{~ms}$ and $17 \mathrm{~ms}$ were probed. The number of slices in the indirect dimension was 256, with 512 transients averaged per slice with a $t_{1}$ increment of $40 \mu \mathrm{s}$. Phase-sensitive detection in $t_{1}$ was achieved through the use of States-TPPI.

While studying the ageing of the $\mathrm{Li}_{0.5} \mathrm{VOPO}_{4} .2 \mathrm{H}_{2} \mathrm{O}$, we carried out systematically, at every step of the ageing process, ${ }^{7} \mathrm{Li}$ MAS NMR, XRD and TGA experiments in order to combine all the information on given a sample at a given ageing stage.

\section{Results and discussion}

\section{1- Structure of $\mathrm{Li}_{1} \mathrm{VOPO}_{4} .2 \mathrm{H}_{2} \mathrm{O}$}

$\mathrm{LiVOPO}_{4} \cdot 2 \mathrm{H}_{2} \mathrm{O}$ was first mentioned by Jacobson et al. who synthesized the compound by redox intercalation reactions of $\mathrm{VOPO}_{4} \cdot 2 \mathrm{H}_{2} \mathrm{O}$. A tetragonal cell with $\mathrm{a}=6.350 \AA$ and $\mathrm{c}=$ $12.811 \AA$ was proposed but no structural model could be extracted from powder X-ray diffraction at the time. [10]

$\mathrm{LiVOPO}_{4} \cdot 2 \mathrm{H}_{2} \mathrm{O}$ was also mentioned by Dupre et al. [11]. The compound was, in this case, obtained by electrochemical cycling of $\mathrm{VOPO}_{4} .2 \mathrm{H}_{2} \mathrm{O}$ but no structural information was given. Finally the structure of LiVOPO $_{4} \cdot 2 \mathrm{H}_{2} \mathrm{O}$ has been described in 2012 by Hameed et $a l$. [12] and was used to synthetize $\alpha_{1}-\mathrm{LiVOPO}_{4}$ by dehydration at low temperature.

31P solid state NMR experiments were performed and showed two isotropic signals (86 ppm and $57 \mathrm{ppm}$ ) - Figure 1 - indicating to two independent positions for the phosphorus atoms. A fit of the ${ }^{31} \mathrm{P}$ spinning sideband pattern is presented in SI Figure 1, it shows two phosphorus signals with different isotropic shifts, identical anisotropies and equivalent integrated intensities. At the higher spinning rate, we observed a very weak splitting (estimated to $500 \mathrm{~Hz}$ )) for the two signals at 86 and $57 \mathrm{ppm}$. The origin of this splitting could be attributed to J-coupling to the ${ }^{51} \mathrm{~V}$ nuclei connected to the phosphate groups.

Since all the vanadium ions are paramagnetic $\left(3 \mathrm{~d}^{1}\right.$, vanadium $4+$ only) for a lithium amount of $\mathrm{x}=1$, the origin of these two phosphorus signals is structural and cannot be the consequence of the magnetic state of the neighbouring vanadium atoms. This observation implies that the published structural model should be revisited.

Since the ${ }^{31} \mathrm{P}$ NMR experiments clearly indicated two distinct phosphorus environments with equal population (SI Figure 1), the structural description in space group Cmca, for which the phosphorus atom belongs to one Wyckoff position, is no longer suitable. 
In this context, we performed a re-examination of the structure of $\mathrm{LiVOPO}_{4} \cdot 2 \mathrm{H}_{2} \mathrm{O}$. We synthetized a single crystal of $\mathrm{LiVOPO}_{4} \cdot 2 \mathrm{H}_{2} \mathrm{O}$, as described in the experimental section, and collected a set of X-ray reflections.

A careful scrutiny of the single-crystal X-ray diffraction data revealed the presence of a few weak $h 0 l, l$ odd reflections, which preclude the $c$ glide plane orthogonal to the $\mathrm{b}$ axis present in the Cmca space group selected by Hameed et al. [12] At this stage, two possibilities were raised to reinterpret the structural model, i.e., the use of a supercell to fit with the number of symmetry-independent atoms or the selection of suitable space groups in order to deal with a crystal symmetry compatible with our NMR spectroscopic and X-ray reflection new measurements. The analysis of Bragg intensities revealed that no additional weak reflections could allow choosing a supercell. Therefore, the examination of systematic absences would inform about a symmetry change only. The systematic absences of the few 00l, l odd, reflections suggested the existence of a 21 screw axis parallel to the $\mathrm{c}$ axis. It results in describing the crystal structure of $\mathrm{LiVOPO}_{4} \cdot 2 \mathrm{H}_{2} \mathrm{O}$ using the space-group $C 222_{1}$, a subgroup of $C m c a$. In such a case, the structure solution clearly evidenced two crystallographically independent positions for the phosphorus atoms and only one for lithium cation, which is consistent with the solid state NMR, experiments. The ${ }^{7} \mathrm{Li}$ experiment not showing more than one lithium site is provided in SI Figure 2. The structure refinement using this space group led to a final $\mathrm{R}$ factor of 0.044 , with $w R=0.118$. By the combination of X-ray diffraction and NMR spectroscopy, we can therefore discard the $\mathrm{Cmca}$ space group selected by Hameed et al. [12] in favour of a space group with a lower symmetry. A CIF file of the structure is given in SI.

Crystal structure of $\mathrm{LiVOPO}_{4} \cdot 2 \mathrm{H}_{2} \mathrm{O}$ and discussion of the lithium intercalation sites offered by this structural model.

The 2D-structure of $\mathrm{LiVOPO}_{4} \cdot 2 \mathrm{H}_{2} \mathrm{O}$, displayed in the SI Figure 3, consists of $\mathrm{VO}\left(\mathrm{H}_{2} \mathrm{O}\right) \mathrm{PO}_{4}$ layers of vertex-sharing $\mathrm{VO}_{6}$ octahedra and $\mathrm{PO}_{4}$ tetrahedra with interlayer $\mathrm{Li}^{+}$and water molecules. Within the layers each vanadium octahedron shares its four equatorial oxygen atoms with four different $\mathrm{PO}_{4}{ }^{3-}$ groups. The two remaining axial oxygens are the vanadyl oxygens $\left(d_{v 1=06}=1.635(11) \AA\right.$ and $d_{v 2=03}=1.535(10) \AA$ ) and the water molecules coordinated trans to this $\left(\mathrm{d}_{\mathrm{v} 1-\mathrm{Ow} 1}=2.6424(104) \AA\right.$ and $\mathrm{d}_{\mathrm{v} 2-\mathrm{Ow} 2}=2.5539$ (91) $\AA$ ). The octahedra are then greatly distorted, whereas the $\mathrm{PO}_{4}$ tetrahedra present only a slight distortion. This has been generally noticed in the $\mathrm{M}_{\mathrm{x}} \mathrm{VOPO}_{4} \cdot 2 \mathrm{H}_{2} \mathrm{O}$ compounds [23]. The second type of water molecules are located in the interlayer space and are linked by hydrogen bonds to two layers simultaneously (Figure 2). The lithium cation occupies one crystallographic site. Its octahedral coordination is defined by one vanadiumcoordinated water molecule, one vanadyl group, two interlayer water molecules and two V-O-P bridging oxygens.

The $\mathrm{Li}_{\mathrm{x}} \mathrm{VOPO} 4.2 \mathrm{H}_{2} \mathrm{O}$ compounds are prepared by lithium insertion between the layers of $\mathrm{VOPO}_{4} \cdot 2 \mathrm{H}_{2} \mathrm{O}$ [10]. The lithium-intercalated phases are obtained under the form of poorly crystalline powders, which hinders the determination of their crystal structures. The only reliable structural information one can extract from these X-ray powder diffraction patterns is an interlayer distance. The parent layered structures with $\mathrm{x}=0$ and $\mathrm{x}=1$ can be obtained as single crystals and present crystal structures well refined by X-ray diffraction experiments. The two end-member structures contain similar $\mathrm{VO}\left(\mathrm{H}_{2} \mathrm{O}\right) \mathrm{PO}_{4}$ 
layers. It is beyond any doubt that the intermediate structures of the $\mathrm{Li}_{\mathrm{x}} \mathrm{VOPO}_{4} \cdot 2 \mathrm{H}_{2} \mathrm{O}$ phases present the same layers as found in the $\mathrm{x}=0$ and $\mathrm{x}=1$ phases.

During the progressive lithium intercalation, the layers should mainly differ by the ratio of the number of vanadium 4+ with respect to number of vanadium $5+$ (one $\mathrm{V}^{4+}$ per one $\mathrm{Li}^{+}$intercalated per formula unit). The organisation of the lithium ions and water molecules between the layers remains completely unknown and a detailed analysis of the structure of the parent compounds is first step toward the interpretation of the NMR data.

If we closely observe the structure of $\mathrm{VOPO}_{4} \cdot 2 \mathrm{H}_{2} \mathrm{O}$, several empty octahedral sites can be evidenced geometrically similar to the one occupied by the lithium in the $\mathrm{Li}_{1} \mathrm{VOPO}_{4} .2 \mathrm{H}_{2} \mathrm{O}$ structure. Figure 3a clearly shows that, considering one layer, four symmetry-equivalent octahedral sites exist around the vanadyl group (upper part of the layer), and four more sites are located around the water molecule located trans to the $\mathrm{V}=\mathrm{O}$ bond (lower part) Figure $3 \mathrm{~b}$. In addition, each coordination site is shared between two vanadium atoms, which are potentially different in term of oxidation state. This results in a large number of interlayer octahedral sites, which can potentially be occupied by lithium cations upon the intercalation process (Figure $3 \mathrm{a}$ and $3 \mathrm{~b}$ ). In the case of $\mathrm{LiVOPO}_{4} .2 \mathrm{H}_{2} \mathrm{O}, 1 / 4$ of the sites are occupied in an ordered fashion. This induces a relative displacement of two adjacent layers resulting in two edge sharing octahedra filled by lithium cations (Figure 2 and SI Figure 6). It is important to note that in the case of $\mathrm{VOPO}_{4} \cdot 2 \mathrm{H}_{2} \mathrm{O}$ the vanadium cations are diamagnetic $\left(\mathrm{V}^{5+}, 3 \mathrm{~d}^{0}\right)$, while in $\mathrm{LiVOPO}_{4} \cdot 2 \mathrm{H}_{2} \mathrm{O}$ the vanadium cations are paramagnetic $\left(\mathrm{V}^{4+}, 3 \mathrm{~d}^{1}\right)$. In the case of $\mathrm{Li}_{\mathrm{x}} \mathrm{VOPO}_{4} \cdot 2 \mathrm{H}_{2} \mathrm{O}$ with $0<\mathrm{x}<1$ a mixed valence is observed with a distribution of $\mathrm{V}^{4+}$ and $\mathrm{V}^{5+}$ giving a general formula respecting a neutral charge balance $\mathrm{Li}_{\mathrm{x}}\left(\mathrm{V}^{5+}{ }_{(1-\mathrm{x})} \mathrm{V}^{4+}{ }_{\mathrm{x}}\right) \mathrm{OPO}_{4} \cdot 2 \mathrm{H}_{2} \mathrm{O}$.

\section{2-Higher hydrate lithium-intercalated phases}

As described in the experimental section, the intercalation process involves a filtration of the intercalated sample with water. The compounds obtained after filtration were dried in a desiccator and immediately analysed by X-ray diffraction and TGA.

The compound "as-prepared" presents a larger interlayer space than the compound analysed one day (or more) after the synthesis (SI Figure 5). The thermogravimetric analysis of the as-prepared compound exhibits two distinct weight losses corresponding respectively to five and two water molecules (Table 1 and SI Figure 8). The ${ }^{7} \mathrm{Li}$ NMR MAS spectra of three $\mathrm{x}=0.5$ compounds are presented in Figure 5 (sample as prepared, 1 day and 22 days old). The general aspect of the spectra is the same reflecting closely related lithium environments. The as-prepared sample with a water content estimated to $7 \mathrm{H}_{2} \mathrm{O}$ presents a lithium spectrum similar to the other compounds having a smaller water content $\left(2 \mathrm{H}_{2} \mathrm{O}\right)$. The exact amount of additional water between the layers remains questionable since it is difficult to distinguish by TGA between the adsorbed water molecules on the grain surface and the water molecules taking part of the crystal structure. However, this additional water loss is reproducible and a similar behaviour has been already reported [9]. The evolution of the interlayer distance associated with this additional hydration is also strongly in favour of a higher water content than two molecules. The possible interlayer lithium sites are located close to the vanadium phosphate layers with a coordination sphere completed by water molecules. The main 
difference between the ${ }^{7} \mathrm{Li} \mathrm{NMR}$ signal of the higher hydrate phase and the dihydrate is the appearance of two additional signals in the dehydrate phase (at 25 and $16 \mathrm{ppm}$ ) along with a decrease in the intensity of a contribution at 3ppm. In the absence of a crystal structure, it remains difficult to get any further in the interpretation of the changes, however we can conclude that the dehydration process leaves the lithium environments relatively unmodified on the local scale.

\section{3- Lithium intercalation and interlayer dynamics in $\mathrm{Li}_{x} \mathrm{VOPO}_{4} .2 \mathrm{H}_{2} \mathrm{O}$ for $0<\mathrm{x}<1$}

The structural and dynamic organisation corresponding to the $\mathrm{Li}$ intercalation in $\mathrm{Li}_{\mathrm{x}} \mathrm{VOPO}_{4} .2 \mathrm{H}_{2} \mathrm{O}$ is connected to three main sources of disorder:

- The local arrangement of the lithium ions among the four possible lithium positions around every vanadium pseudo-octahedron. When the loading is lower than $\mathrm{x}=1$ the long range ordering observed for the fully charged compound is no longer strictly constrained.

- Another source of disorder arises from the respective location of the vanadium ions at various oxidation states [24]. For a lithium content of $x=0.5$, the charge balance imposes an equal number of $\mathrm{V}^{4+}$ (electronic structure $\left.3 \mathrm{~d}^{1}\right)$ and $\mathrm{V}^{5+}\left(3 \mathrm{~d}^{0}\right)$ ions. The local arrangement of $\mathrm{V}^{4+}$ versus $\mathrm{V}^{5+}$ is not necessarily periodic and is likely to have an impact on the location of the lithium ions.

- Finally, another source of disorder within the interspace layer lies on the dynamics of the water molecules. This dynamics have been documented by deuterium NMR and exhibits sub-microsecond timescale dynamics [16].

The main observation of the effect of progressive intercalation of lithium between the layers is a decrease in the interlayer distance. For $\mathrm{VOPO}_{4} \cdot 2 \mathrm{H}_{2} \mathrm{O}$, it was measured at 7.40 $\AA$. Upon intercalation, the distance was evaluated between $7.19 \AA$ for $x=0.17$ and $6.68 \AA$ for $x=0.5$. This change in the interlayer space can be easily evidenced by X-ray powder diffraction (SI Figure 7) [10].

The MAS ${ }^{7} \mathrm{Li}$ NMR experiments (14 T) presented in Figure 4 for two different lithium contents ( $\mathrm{x}=0.17$ and $\mathrm{x}=0.5$, verified by spectrophotometric absorption measurements) shows the occupation of several different sites (SI Figure 6). These two compounds have very different X-ray powder patterns and, therefore, cannot be considered as a mixture of crystallites with various Li contents (SI Figure 7). For a small amount of intercalated lithium ( $x=0.17)$, we observed a signal at $-2 \mathrm{ppm}$. For an increased level of intercalated lithium $(x=0.5)$, the signal at $-2 \mathrm{ppm}$ is still present along with a series of well-defined peaks at 26, 18, 0 and -11 ppm reflecting a well-defined local organisation and a preferential filling of lithium sites.

Despite the paramagnetic nature of the compound, the values of $\mathrm{T}_{2}$ relaxation times were long enough to consider running two-dimensional dipolar correlation NMR experiments in order to get a better description of the local environments. We were not able to collect information on the vicinity of the different lithium by using dipolar correlation experiments (RFDR). However, 2D exchange ${ }^{7} \mathrm{Li}$ experiments were particularly successful to describe a chemical exchange between lithium sites.

For a given $\mathrm{Li}_{0.5} \mathrm{VOPO}_{4} .2 \mathrm{H}_{2} \mathrm{O}$ sample, the evolution of the ${ }^{7} \mathrm{Li} 1 \mathrm{D}$ MAS experiments as function of time after synthesis are reported in Figure 5. The general lineshape as a 
function of ageing remains constant however, intensity differences can be observed between the signals located at 0 and -2 ppm (Figure 5 , insert) when then sample gets older compared to an as-prepared sample. These modifications occur on a time scale of at least several days.

The 2D EXSY spectra with mixing times of 5.3 and $8.5 \mathrm{~ms}$ (longer mixing times were not possible owing to $\mathrm{T}_{2}$ relaxation) are shown in Figure $6 \mathrm{a}$ and $6 \mathrm{~b}$, and clearly demonstrate that dynamic exchange takes place in the compound. The off-diagonal peaks observed in the spectrum recorded with a mixing time of $8.5 \mathrm{~ms}$ shows a chemical exchange taking place between almost all the sites except between the group of signals between 26 and $18 \mathrm{ppm}$ and the group between 0 and $2 \mathrm{ppm}$. For a shorter mixing time (5.3 ms), we are clearly losing the observation of an exchange between the lithium at $-11 \mathrm{ppm}$ and the lithium at 26 and $18 \mathrm{ppm}$. Interestingly, when we performed the same experiment on the same sample three weeks later, the results became very significantly different. If we compare the corresponding figures with the same mixing times (respectively Figure $6 \mathrm{a}$ versus $6 c$ and $6 b$ versus $6 d$ ), it clearly appears that the sample ageing is leading to a very significant modification of the lithium exchanges. More precisely, we initially (one day old sample) observe exchange between the lithium located at 25 and 16 ppm together and with the lithium at -13 ppm. After 22 days, there is no more exchange involving the signal at $-13 \mathrm{ppm}$ while the exchange remains between the lithium observed at 25 and $16 \mathrm{ppm}$. In conclusion, even after 22 days, we can still observe some dynamic behaviour in the 2D EXSY experiments but, at that stage, the ${ }^{7} \mathrm{Li}$ 1D NMR spectra are not showing intensity modifications of the different contributions to the overall signal. An evaluation of the lithium exchange rate in the final compound has been carried out by fitting the intensity of the 2D EXSY cross peaks as a function of the mixing time [22] and is presented in SI Figure 4. The obtained exchange rate $(\mathrm{k}=730.97 \pm 41.77 \mathrm{~Hz})$ indicates a slow exchange between two of the lithium sites (at 26 and $18 \mathrm{ppm}$ ) at room temperature in the stabilised compound 22 days after synthesis.

The lithium NMR experiments can therefore give us a good description of the behaviour of the ions intercalated between the layers. In order to get a better understanding of the local organisation of the layers themselves (in which the main degree of freedom is the respective location of the paramagnetic and diamagnetic vanadium ions), we carried out ${ }^{31} \mathrm{P}$ NMR experiments as a function of aging in parallel with the ${ }^{7} \mathrm{Li} \mathrm{NMR}$ experiments. The results are presented in Figure 7. The ${ }^{31} \mathrm{P}$ NMR signal of the $\mathrm{Li}_{0.5} \mathrm{VOPO}_{4} .2 \mathrm{H}_{2} \mathrm{O}$ compound one day after preparation (Figure 7, below) presents a complex structure revealing the influence of the paramagnetic vanadium atoms surrounding the probed nucleus. A tentative assignation have been proposed by Roca et al for a ${ }^{31} \mathrm{P}$ spectrum obtained in the structurally related $\mathrm{Na}_{0.5} \mathrm{VOPO}_{4} .2 \mathrm{H}_{2} \mathrm{O}$ compound. In the two structures, each phosphorus is surrounded by four vanadium ions (either $\mathrm{V}^{4+}$ or $\mathrm{V}^{5+}$ ). In a first approximation, the overall shift would be dominated by the presence, around a given phosphorus, of paramagnetic $\mathrm{V}^{4+}$ ions as a first neighbour. The fine structure observed in our case probably reveals a smaller contribution related to the presence of $\mathrm{V}^{4+}$ at a longer distances (second neighbour vanadium ions). On average, with a lithium charge of 0.5 per formula unit, each phosphorus atom is statistically surrounded by two vanadium $4+$ and two vanadium $5+$ so it seems reasonable to attribute the main contribution to NMR spectra to this type of local environment. The other main contributions could therefore by attributed to phosphorus with one paramagnetic neighbour (less paramagnetically shifted signal) and three paramagnetic neighbour (more shifted signal). Interestingly, when we compare the ${ }^{31} \mathrm{P}$ spectra for a 
$\mathrm{Li}_{0.5} \mathrm{VOPO}_{4} .2 \mathrm{H}_{2} \mathrm{O}$ one and 22 days after synthesis, we observed a very significant modification of the population of the different phosphorus signals. This observation reveals a charge ordering mechanism of the vanadium $4+$ and $5+$ within the layers. This charge ordering mechanism occurring within the layers evidenced by ${ }^{31} \mathrm{P}$ NMR is presumably connected to the lithium ordering mechanism between the layers evidenced by ${ }^{7} \mathrm{Li} \mathrm{NMR}$.

Considering the two NMR observations: the ageing is observable between the layers by intensity changes in the ${ }^{7} \mathrm{Li}$ 1D MAS NMR experiments, by strong modifications in the low frequency exchange (millisecond time scale) as evidenced by the EXSY experiments and within the layers by ${ }^{31} \mathrm{P}$ MAS NMR.

At this stage of the work, the remaining question was mainly to make sure that we were dealing during all the aging process with a single phase, which was not presenting any water content modification or phase transition.

Thermogravimetric analysis carried out along the aging process confirmed the absence of water content modifications.

In this context, we carefully examined our X-ray powder diffraction data searching for a confirmation of the structural changes observed at a local scale by NMR spectroscopy but, this time, using a method involving both a time and a spatial averaging of the description of the structure. The trace of a powder pattern is the radial distribution in reciprocal space of the total coherent scattering from a powder sample, in which a Bragg reflection is generated by a specific set of lattice planes. Among parameters defining such "Bragg peak", its position is determined by the unit cell dimensions, and its intensity (area) is the Fourier transform of the electron density contributing to the diffraction by the set of the lattice planes (structure factor). In Figure 8, it is clear that ageing $\mathrm{Li}_{0.5} \mathrm{VOPO}_{4} .2 \mathrm{H}_{2} \mathrm{O}$ sample over three weeks did not affect the peak positions, i.e., the unit cell dimensions remain constant. On the other hand, a few intensities seemed to be slightly affected. In order to exclude counting statistics errors for these small variations, integrated intensities (area) of significant diffraction lines have been extracted from the two related diffraction patterns. Intensity ratio of the first reflection at $13.257^{\circ}(2 \theta)$ was normalized to 1 for the two patterns. The normalization factor was applied to the other considered intensity ratios. Intensity ratio of peaks 1 and 3 are comparable within $4 \sigma(\mathrm{I})$, as expected for harmonic Bragg peaks. On the contrary, intensity ratio greatly differs between non-harmonic reflections as seen in Table 2, i.e., the variation of intensities are independent from counting statistic errors. Thus, the peak 2 intensity increases while that of peak 5 decreases upon ageing. This fact is related to the modification of the structure factor of Bragg reflections, in agreement with the change in position of the lithium cations.

\section{Conclusion}

We employed a combination of solid state NMR spectroscopy and X-ray diffraction to get a better understanding of the lithium intercalation in a layered vanadium phosphate compound. Despite the paramagnetic nature of the vanadium ions at the oxidation state $4+$, the relatively limited anisotropies induced by the paramagnetism allowed the use of MAS techniques at standard spinning rates $(30 \mathrm{kHz})$. A conjunction of short $\mathrm{T}_{1}$ 
relaxation times (tens of miliseconds) and relatively long $\mathrm{T}_{2}$ (a few millisecond time scales) allowed us to carry out two dimensional exchange ${ }^{7} \mathrm{Li} \mathrm{NMR}$ experiments giving access to low frequency site exchange in the intercalated compounds. The combination of single crystal X-ray diffraction and NMR results allowed us to revisit the structural description of the fully intercalated compound $\mathrm{Li}_{1} \mathrm{VOPO}_{4} \cdot 2 \mathrm{H}_{2} \mathrm{O}$. The partially intercalated compounds are only available under the form of microcrystalline powders. Detailed ${ }^{7} \mathrm{Li}$ NMR experiments carried out for a $50 \%$ lithium intercalation compound showed a series of discrete local environments for the lithium ions. This local organisation is not necessarily periodic and therefore gives only small modifications on the X-ray powder diffraction patterns. Beyond the structural description of the lithium intercalation local ordering, this work allowed us to describe the dynamics of the interlayer species at very different timescales. Site exchanges on the millisecond timescale were established with ${ }^{7} \mathrm{Li}$ EXSY NMR experiments. By running EXSY experiments on the same sample at several weeks interval, we were able to demonstrate a decrease of the exchange between sites during the ageing of the intercalated compound. This observation correlates with static observation provided by ${ }^{7} \mathrm{Li} 1 \mathrm{D}$ NMR and powder XRD. Additionally to the lithium charge ordering between the layers, ${ }^{31} \mathrm{P}$ NMR provided the evidence of a $\mathrm{V}^{4+}$ versus $\mathrm{V}^{5+}$ charge ordering within the layers taking place in $\mathrm{Li}_{0.5} \mathrm{VOPO}_{4} .2 \mathrm{H}_{2} \mathrm{O}$ upon aging on a time scale of at least several days.

\section{Acknowledgments}

This work benefited from a grant from Agence Nationale de la Recherche (ANR MOSAIC 13-BS08-0018-01). FEDER, Région Bretagne, Rennes Métropole, CG35 and CNRS contributed to the purchase of NMR spectrometers and X-ray powder diffraction diffractometer.

\section{References}

[1] N. Dummer, J. Bartley, and G. Hutchings, Vanadium phosphate materials as selective oxidation catalysts, 54 (2011), 189-247 https://doi.org/10.1016/B978-0-12$\underline{387772-7.00004-6}$

[2] J.-M. Ateba Mba; C. Masquelier; E. Suard; L. Croguennec, Synthesis and Crystallographic Study of Homeotypic $\mathrm{LiVPO}_{4} \mathrm{~F}$ and $\mathrm{LiVPO}_{4} \mathrm{O}$ Chemistry of Materials 24 (2012) 1223-1234. https://doi.org/10.1021/cm3003996

[3] J. Barker; R. K. B. Gover; P. Burns; A. Bryan; M. Y. Saidi; J. L. Swoyer, Structural and electrochemical properties of lithium vanadium fluorophosphate, LiVPO 4F, Journal of Power Sources (2005), 146, (1-2), 516-520. https://doi.org/10.1016/j.jpowsour.2005.03.126

[4] S. C. Yin; H. Grondey; P. Strobel; M. Anne; L. F. Nazar, Electrochemical Property: Structure Relationships in Monoclinic $\mathrm{Li}_{3-\mathrm{y}} \mathrm{V}_{2}\left(\mathrm{PO}_{4}\right)_{3}$, Journal of the American Chemical Society (2003), 125, (34), 10402-10411. https://doi.org/10.1021/ja034565h 
[5] C. Wu; X. Lu; L. Peng; K. Xu; X. Peng; J. Huang; G. Yu; Y. Xie, Two-dimensional vanadyl phosphate ultrathin nanosheets for high energy density and flexible pseudocapacitors, Nature Communications 4 (2013) 2431-2438. https://doi.org/10.1038/ncomms3431

[6] L. Beneš, K. Melánová, J. Svoboda, V. Zima, Intercalation chemistry of layered vanadyl phosphate: a review, J Incl. Phenom. Macrocyclic Chem., 73 (2012) 33-53. https://doi.org/10.1007/s10847-011-0097-1

[7] G. Ladwig, Über die Konstitution des VPO5(·nH20) Z.Anorg. Allg. Chem. (1965), 338, 266. https://doi.org/10.1002/zaac.19653380506

[8] Tietze, H. R., The crystal and molecular structure of oxovanadium(V) orthophosphate dihydrate, $\mathrm{VOPO}_{4}, 2 \mathrm{H}_{2} \mathrm{O}$, Aust. J. Chem. (1981), 34, 2035. https://doi.org/10.1071/CH9812035

[9] J. W. Johnson and A. J. Jacobson, Redox Intercalation Reactions of VOPO4.2H2O, Angew. Chem. Int. Ed. Engl. 22 (1983) 412-413. https://doi.org/10.1002/anie.198304121

[10] A. J. Jacobson, Jack W. Johnson, J. F. Brody, J. C. Scanlon, and J. T. Lewandowski, Redox intercalation reactions of vanadium oxide phosphate dihydrate (VOPO4.2H20) with mono- and divalent cations, Inorg. Chem. 24 (1985) 1782-1787, https://doi.org/10.1021/ic00206a015

[11] a) V. Zima, L. Benes, R. Siskova, P. Fatena, J. Votinsky, Intercalation of VOP04·2H2O with lithium ions, Solid State Ionics 67 (1994) 277-280. https://doi.org/10.1016/01672738(94)90017-5,

b) A. Chauvel, M. E. de Roy, J. P. Besse, A. Benarbia, A. Legrouri and A. Barroug, Redox intercalation of alkali metals into vanadyl phosphate dehydrate, Mater. Chem. Phys. 40 (1995) 207-211. https://doi.org/10.1016/0254-0584(95)01482-9

c) N. Dupré, J. Gaubicher, J. Angenault, M. Quarton, Electrochemical study of intercalated vanadyl phosphate, J. Solid State Electrochem. 8 (2004) 322-329. https://doi.org/10.1007/s10008-003-0456-y

[12] A. S. Hameed, M. Nagarathinam,a M. V. Reddy, B. V. R. Chowdari and J. J. Vittal, Synthesis and electrochemical studies of layer-structured metastable $\alpha$ I-LiVOPO4 J. Mater. Chem., 22 (2012) 7206-7213 https://doi.org/10.1039/C2JM00062H

[13] M. F. V. Hidalgo, Y.-C. Lin, A. Grenier, D. Xiao, J. Rana, R Tran, H. Xin, M. Zuba, J. Donohue, F. O. Omenya, I.-H. Chu, Z. Wang, X. G. Li, N. A. Chernova, K. W. Chapman, G Zhou, L. Piper, S. P. Ong and M. S. Whittingham. Rational synthesis and electrochemical performance of LiVOPO4 polymorphs. J. Mater. Chem. A., (2019) Advance Article https://doi.org/10.1039/C8TA12531G

[14] a) R. Gautier, N. Audebrand, E Furet, R. Gautier, E. Le Fur, VOPO ${ }_{4} \cdot \mathrm{H}_{2} \mathrm{O}$ : A Stacking Faults Structure Studied by X-ray Powder Diffraction and DFT-D Calculations, Inorg. Chem., 50 (2011) 4378-4383. https://doi.org/10.1021/ic102473s 
b) R. Gautier, R. Gautier, O Hernandez, N. Audebrand, T. Bataille, C. Roiland, E. ElKaim, L. Le Pollès, E Furet, E. Le Fur, DFT-assisted structure determination of $\alpha 1$ - and $\alpha_{2}-\mathrm{VOPO}_{4}$ : new insights into the understanding of the catalytic performances of vanadium phosphates, Dalton Trans., 42 (2013) 8124-8131.

https://doi.org/10.1039/C3DT50217A

[15] L. Benes and V. Zima, Formation of a disordered layer lattice during the intercalation of water into anhydrous vanadyl phosphate, J. Inclusion Phenom. Molec. Recogn. Chem. 20 (1995) 381-391. https://doi.org/10.1007/BF00708882

[16] K. Takamoto, O., YamadaKoji, and O.Tsutomu, Dynamic Property of $\mathrm{H}_{2} \mathrm{O}$ in Layered $\mathrm{VOPO}_{4} \cdot 2 \mathrm{H}_{2} \mathrm{O}$ Studied by Solid-State NMR, Bull. Chem. Soc. Jpn 79 (2006) 864866. https://doi.org/10.1246/bcsj.79.864

[17] Collect Nonius, Kappa CCD Program Software, Nonius BV, Delft, The Netherlands 1998.

[18] A. Altomare, M. C. Burla, M. Camalli, G. L. Cascarano, C. Giacovazzo, A. Guagliardi, A. G. G. Moliterni, G. Polidori, R. Spagna, SIR97: a new tool for crystal structure determination and refinement, J. Appl. Crystallogr. 32 (1999) 115-119. https://doi.org/10.1107/S0021889898007717

[19] G. M. Sheldrick, A short history of SHELX, Acta Crystallogr. 64 (2008) 112-122. https://doi.org/10.1107/S0108767307043930

[20] L. J. Farrugia, WinGX and ORTEP for Windows: an update, J. Appl. Crystallogr. 45 (2012) 849-854. https://doi.org/10.1107/S0021889812029111

[21] a J. Cuny, J. Yates, R Gautier, E Furet, E Le Fur, L Le Pollès, Electric field gradient calculations in paramagnetic compounds using the PAW approach. Application to ${ }^{23} \mathrm{Na}$ NMR in layered vanadium phosphates, Magn. Reson. Chem., 48 (2010) S171-S175. https://doi.org/10.1002/mrc.2674

b Y. J. Lee, F. Wang, C. P. Grey, ${ }^{6} \mathrm{Li}$ and ${ }^{7} \mathrm{Li}$ MAS NMR Studies of Lithium Manganate Cathode Materials, J. Am. Chem. Soc. 120 (1998)12601-12613.

https://doi.org/10.1021/ja9817794

c Y.J. Lee, F. Wang, S. Mukerjee, J. McBreen, C.P. Grey, ${ }^{6} \mathrm{Li}$ and ${ }^{7} \mathrm{Li}$ Magic-Angle Spinning Nuclear Magnetic Resonance and In Situ X-Ray Diffraction Studies of the Charging and Discharging of $\mathrm{Li}_{x} \mathrm{Mn}_{2} \mathrm{O}_{4}$ at 4 V, J Electrochem Soc, 147 (2000) 803-812. https://doi.org/10.1149/1.1393276 
[22] a) J. Jeener, B.H. Meier, P. Bachmann, R.R. Ernst, Investigation of exchange processes by two-dimensional NMR spectroscopy, J. Chem. Phys. 71 (1979) 4546-4553. https://doi.org/10.1063/1.438208

b) Z. Xu, J. F. Stebbins, Cation Dynamics and Diffusion in Lithium Orthosilicate: TwoDimensional Lithium-6, NMR, Science, $270 \quad$ (1995) 1332-1334. https://doi.org/10.1126/science.270.5240.1332

c) L. S. Cahill, R. P. Chapman, J. F. Britten, and G. R. Goward, 7Li NMR and TwoDimensional Exchange Study of Lithium Dynamics in Monoclinic $\mathrm{Li}_{3} \mathrm{~V}_{2}\left(\mathrm{PO}_{4}\right)_{3}$, J. Phys. Chem. B, 110 (2006) 7171-7177 https://doi.org/10.1021/jp057015+

d) L. J. M. Davis, B. L. Ellis, T. N. Ramesh, L. F. Nazar, A. D. Bain, and G. R. Goward, ${ }^{6}$ Li 1D EXSY NMR Spectroscopy: A New Tool for Studying Lithium Dynamics in Paramagnetic Materials Applied to Monoclinic $\mathrm{Li}_{2} \mathrm{VPO}_{4} \mathrm{~F}$. J. Phys. Chem. C, 115 (2011) 22603-22608. https://doi.org/10.1021/ip2059408

e) R. J. Messinger, M. Ménétrier, E. Salager, A. Boulineau, M. Duttine, D. Carlier, J.M. Ateba Mba, L. Croguennec, C. Masquelier, D. Massiot and M. Deschamps, Revealing Defects in Crystalline Lithium-Ion Battery Electrodes by Solid-State NMR: Applications to $\mathrm{LiVPO}_{4} \mathrm{~F}$, Chem.Mater. (2015), 27, 5212-5221. https://doi.org/10.1021/acs.chemmater.5b01234

[23] E. Le Fur, J. Y. Pivan, Synthesis, crystal structure and magnetic properties of the novel stacking variant lamellar lead oxovanadium phosphate hydrate $0 \mathrm{~Pb}\left(\mathrm{VOPO}_{4}\right)_{2}$ $4 \mathrm{H}_{2} \mathrm{O}$. Crystal chemical relationships with related intercalated $\mathrm{M}\left(\mathrm{VOPO}_{4}\right)_{2} \mathrm{yH}_{2} \mathrm{O}$ compounds J. Mater. Chem., (1999), 9, 2589-2594. https://doi.org/10.1039/A901048C

[24] M. Roca, P. Amoros, J. Cano, M. D. Marcos, J. Alamo, A. Beltrán-Porter, and D. Beltran-Porter, Prediction of Magnetic Properties in Oxovanadium(IV) Phosphates: The Role of the Bridging $\mathrm{PO}_{4}$ Anions, Inorg. Chem. 37 (1998) 3167-3174.

https://doi.org/10.1021/ic971210o 
Table $1: \mathrm{Li}_{0.5} \mathrm{VOPO}_{4}, \mathrm{nH}_{2} \mathrm{O}$ with $2.02<\mathrm{n}<7.26$

\begin{tabular}{|c|c|c|c|}
\hline Status & $\begin{array}{c}\text { Peak position } \\
\left({ }^{\circ} 2 \theta\right)\end{array}$ & $\mathrm{d}$ spacing $(\AA)$ & $\begin{array}{c}\text { Estimation of water } \\
\text { content, } \mathrm{n}\left(\mathrm{mol} \mathrm{H}_{2} \mathrm{O}\right)\end{array}$ \\
\hline $\begin{array}{c}\text { As- } \\
\text { prepared }\end{array}$ & 13.07 & 6.77 & 7.26 \\
\hline 1 days & 13.25 & 6.68 & 2.04 \\
\hline 22 days & 13.26 & 6.67 & 2.02 \\
\hline
\end{tabular}

Table 2 : Peak intensities of $\mathrm{Li}_{0.5} \mathrm{VOPO}_{4} .2 \mathrm{H}_{2} \mathrm{O}$ over one day and three weeks, and their normalized intensity ratio.

\begin{tabular}{|l|l|l|l|l|l|}
\hline $\begin{array}{l}\text { Peak } \\
\text { number }\end{array}$ & $\begin{array}{l}\text { Peak position } \\
\left({ }^{\circ} 2 \theta\right)\end{array}$ & $\begin{array}{l}\mathrm{d} \text { spacing } \\
(\AA)\end{array}$ & $\begin{array}{l}\text { Intensity } \\
\text { after } \\
\text { one day }\end{array}$ & $\begin{array}{l}\text { Intensity after } \\
\text { three weeks }\end{array}$ & $\begin{array}{l}\text { Normalized } \\
\text { intensity } \\
\text { ratio ( } \sigma)\end{array}$ \\
\hline 1 & 13.257 & 6.680 & 38995 & 42839 & $1.000(7)$ \\
\hline 2 & 26.726 & 3.335 & 3887 & 2829 & $1.51(4)$ \\
\hline 3 & 26.978 & 3.305 & 6889 & 8387 & $0.90(2)$ \\
\hline 4 & 28.057 & 3.181 & 267 & 217 & $1.4(1)$ \\
\hline 5 & 28.491 & 3.132 & 194 & 346 & $0.62(6)$ \\
\hline
\end{tabular}


Figure $1:{ }^{31} \mathrm{P}$ MAS NMR Li ${ }_{1} \mathrm{VOPO}_{4} \cdot 2 \mathrm{H}_{2} \mathrm{O}$ recorded at two different MAS rates ( $8 \mathrm{kHz}$, below, and 12 $\mathrm{kHz}$, above). The insert and the arrows on the main figure show the isotropic values. Asterisks denote spinning sidebands.

Figure 2 - Lithium environment between adjacent layers in $\mathrm{Li}_{1} \mathrm{VOPO}_{4} \cdot 2 \mathrm{H}_{2} \mathrm{O}$

Phosphate groups in pink, Vanadium pseudo-octahedra in green, lithium ions in black, oxygen atoms in red and oxygen from water molecules in orange (Hydrogen atoms have been omitted for clarity)

Figure 3 - Empty octahedral (blue) sites in $\mathrm{VOPO}_{4} \cdot 2 \mathrm{H}_{2} \mathrm{O}$ around a vanadium cation a) View along the c axis, b) evidence of octahedral sites from each side of the $\mathrm{VOPO}_{4}$ layer plane. Vanadium pseudooctahedra in green, oxygen atoms in red and oxygen from water molecules in orange

Figure $4-{ }^{7} \mathrm{Li} \mathrm{NMR}$ spectra of $\mathrm{Li}_{x} \mathrm{VOPO}_{4}, 2 \mathrm{H}_{2} \mathrm{O}$ for $\mathrm{x}=0.17$ (below) and $\mathrm{x}=0.5$ (above)

Figure $5:{ }^{7} \mathrm{Li} N M R$ for the higher hydrate $\mathrm{Li}_{0.5} \mathrm{VOPO}_{4} \sim \mathrm{7H}_{2} \mathrm{O}$ and for $\mathrm{Li}_{0.5} \mathrm{VOPO}_{4} .2 \mathrm{H}_{2} \mathrm{O}$ upon aging (1 day and 22 days). Insert presents the evolution of the main signals for $\mathrm{Li}_{0.5} \mathrm{VOPO}_{4} \cdot 2 \mathrm{H}_{2} \mathrm{O}$ upon aging.

Figure $6-{ }^{7} \mathrm{Li}$ EXSY NMR spectra of $\mathrm{Li}_{0.5} \mathrm{VOPO}_{4} \cdot 2 \mathrm{H}_{2} \mathrm{O}$ for a) and b) a one day old sample; c) and d) a 22 days old sample. The experiments a) and c) were carried out a mixing time of $5.3 \mathrm{~ms}$ and the experiments b) and d) of $8.5 \mathrm{~ms}$

Figure $7-{ }^{31} \mathrm{P} \mathrm{NMR} \mathrm{spectra} \mathrm{of} \mathrm{Li}_{0.5} \mathrm{VOPO}_{4} .2 \mathrm{H}_{2} \mathrm{O}$ upon aging after one day (below) and after 3 weeks (above). In the structure, each phosphate group is surrounded by four vanadium ions. Assignation of the ${ }^{31} \mathrm{P}$ signals in three main group for phosphorus atoms surrounded respectively by $1 \mathrm{~V}^{4+} / 3 \mathrm{~V}^{5+}$, $2 \mathrm{~V}^{4+} / 2 \mathrm{~V}^{5+}$ and $3 \mathrm{~V}^{4+} / 1 \mathrm{~V}^{5+}$ (ref. 24)

Figure 8 - XRD patterns of $\mathrm{Li}_{0.5} \mathrm{VOPO}_{4} \cdot 2 \mathrm{H}_{2} \mathrm{O}$ after one day (black) and 22 days (red). 
Figure 1

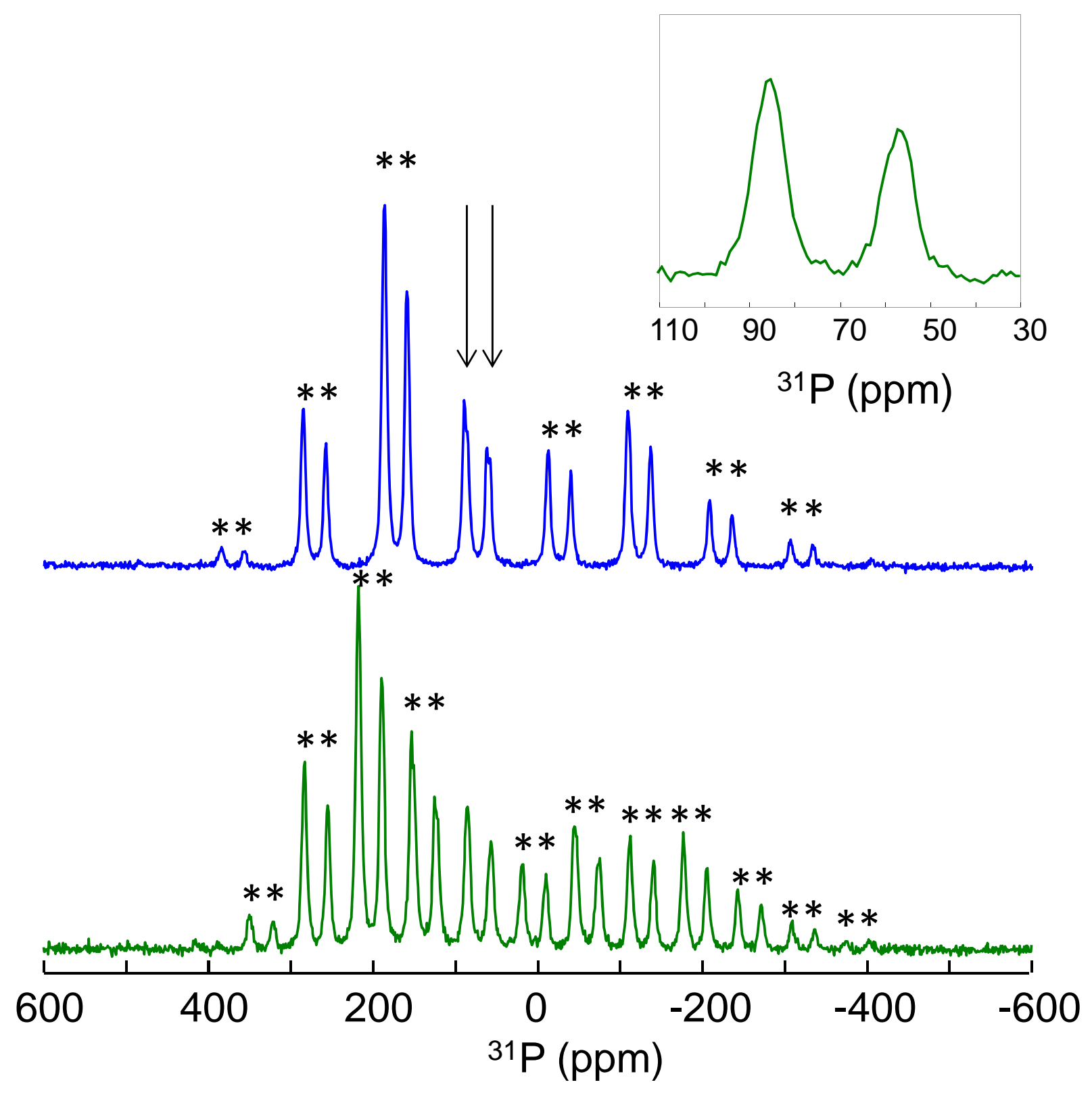


Figure 2

\author{
Oxygen from \\ interlayer water \\ molecules
}

VPO layer 
Figure 3

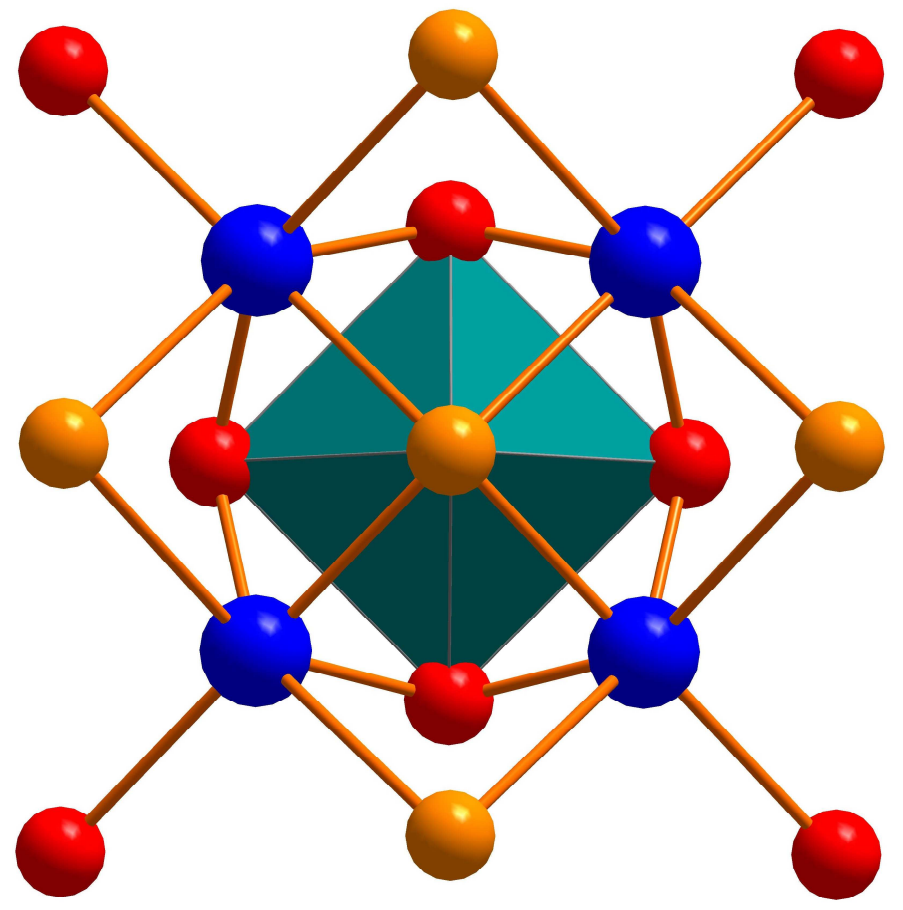

a)

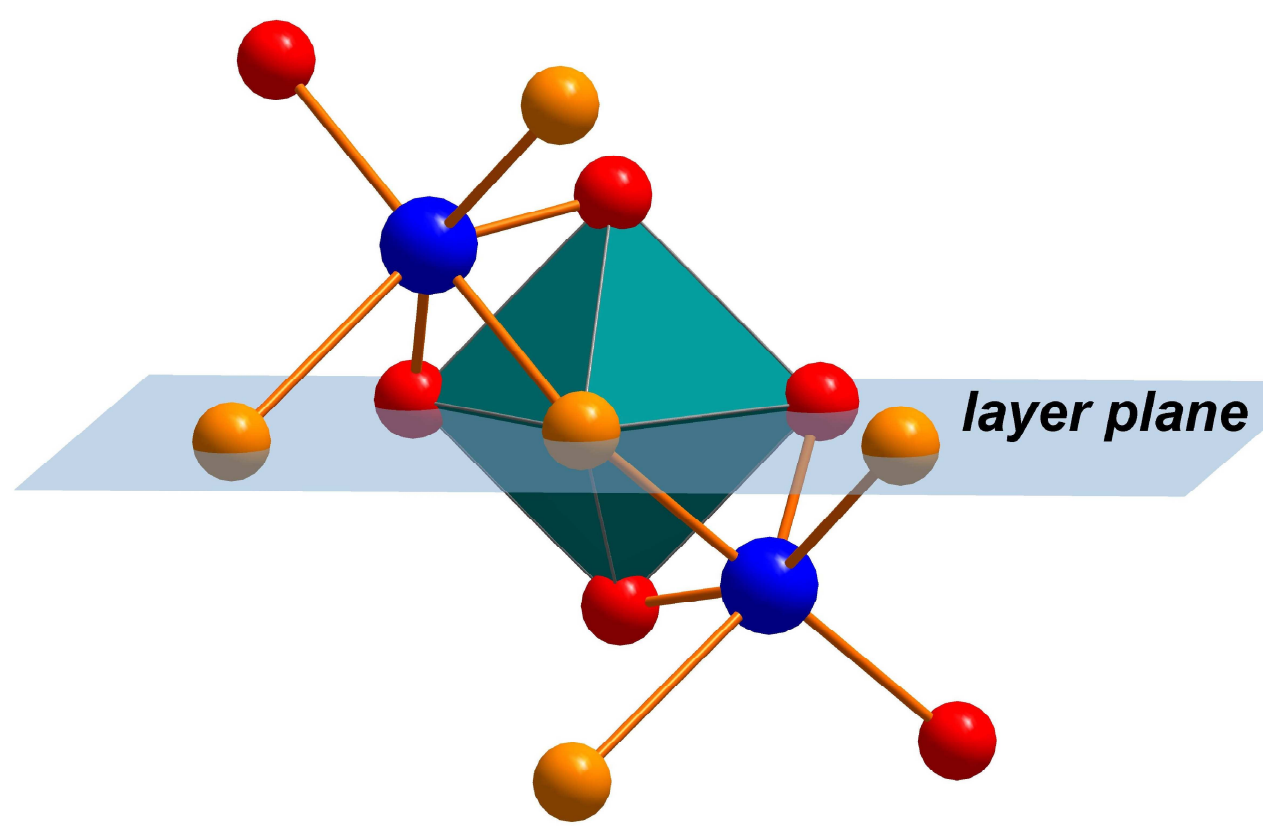

b) 
Figure 4

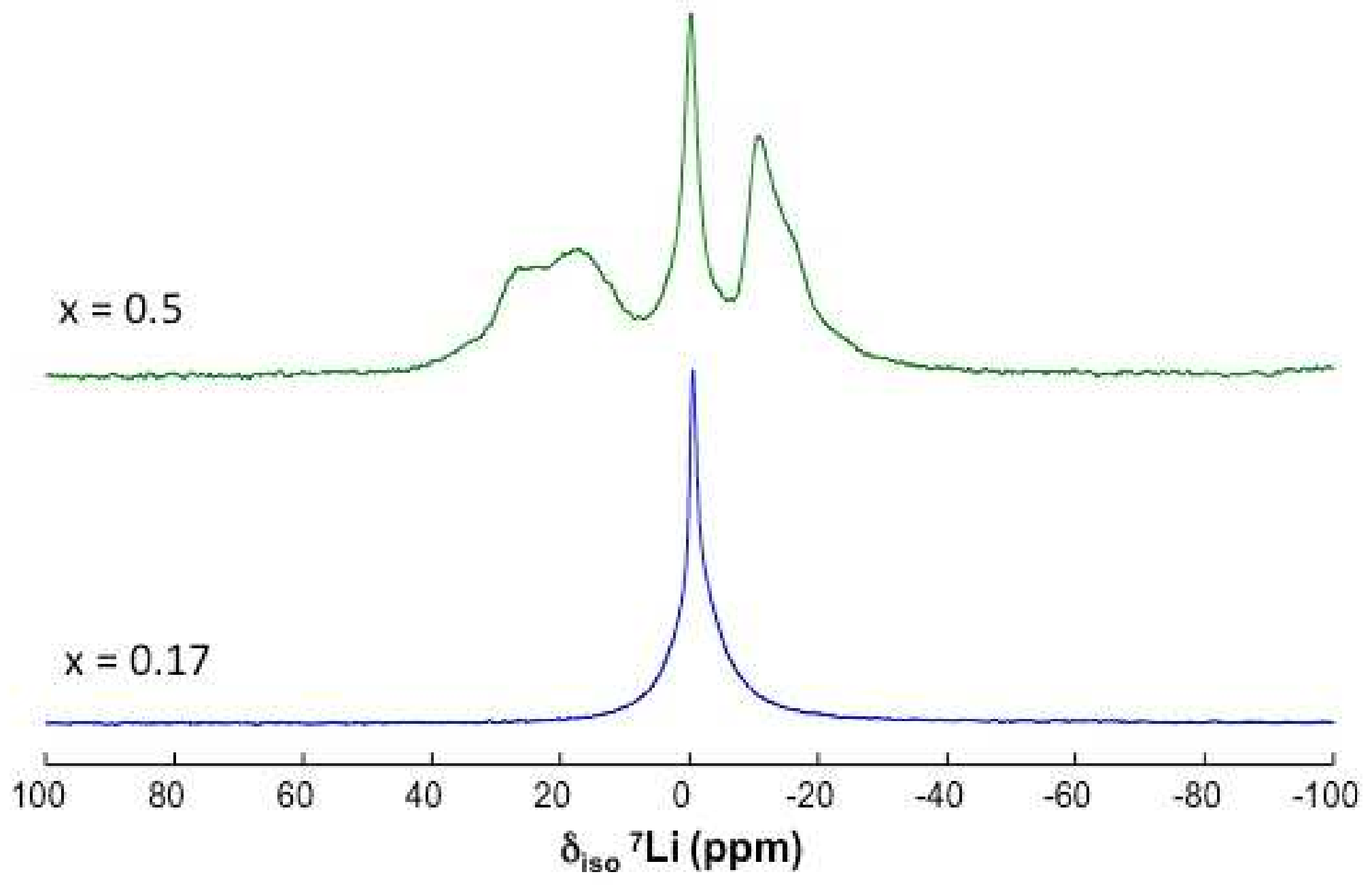


Figure 6
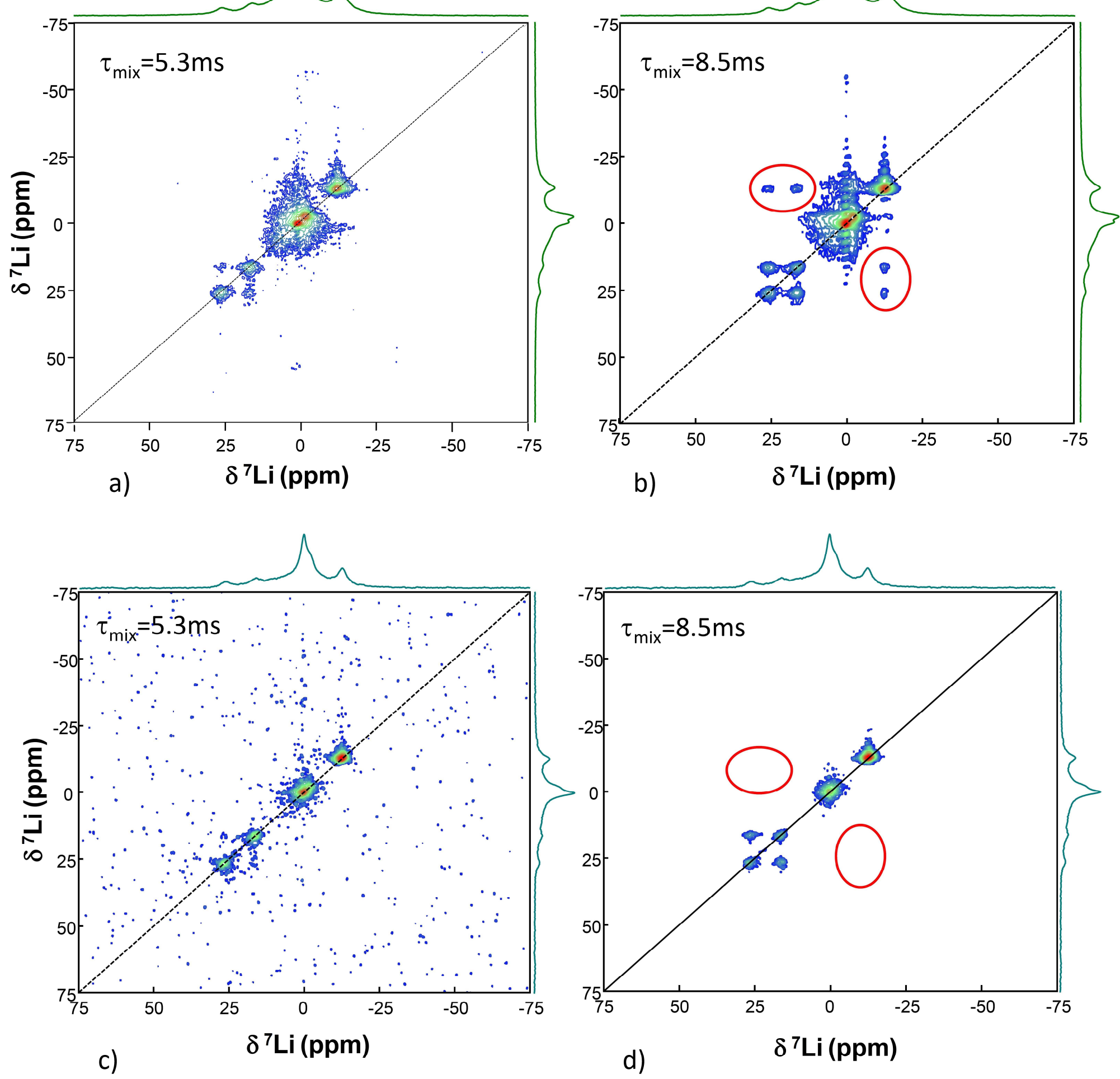
Figure 7

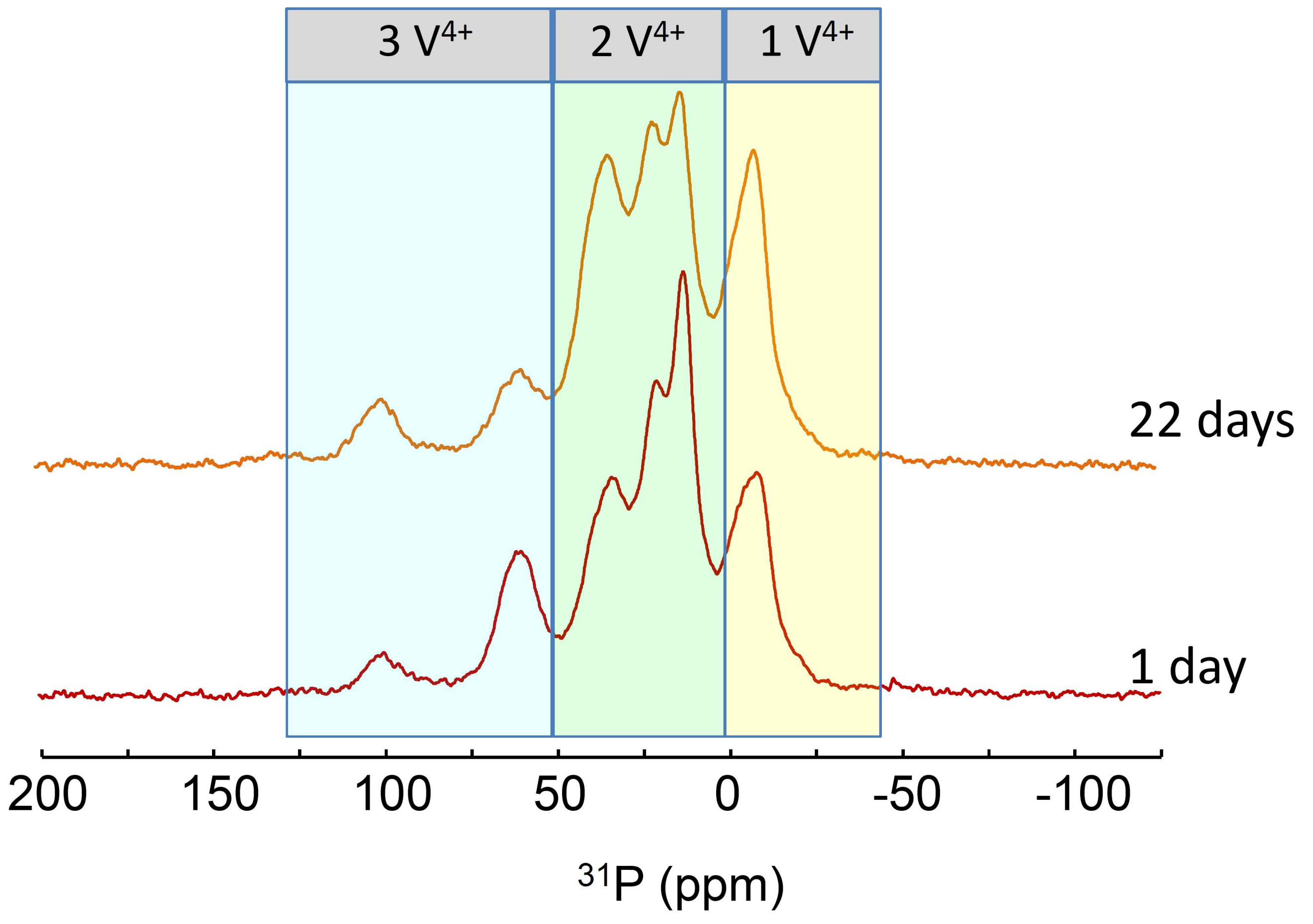


Figure 8

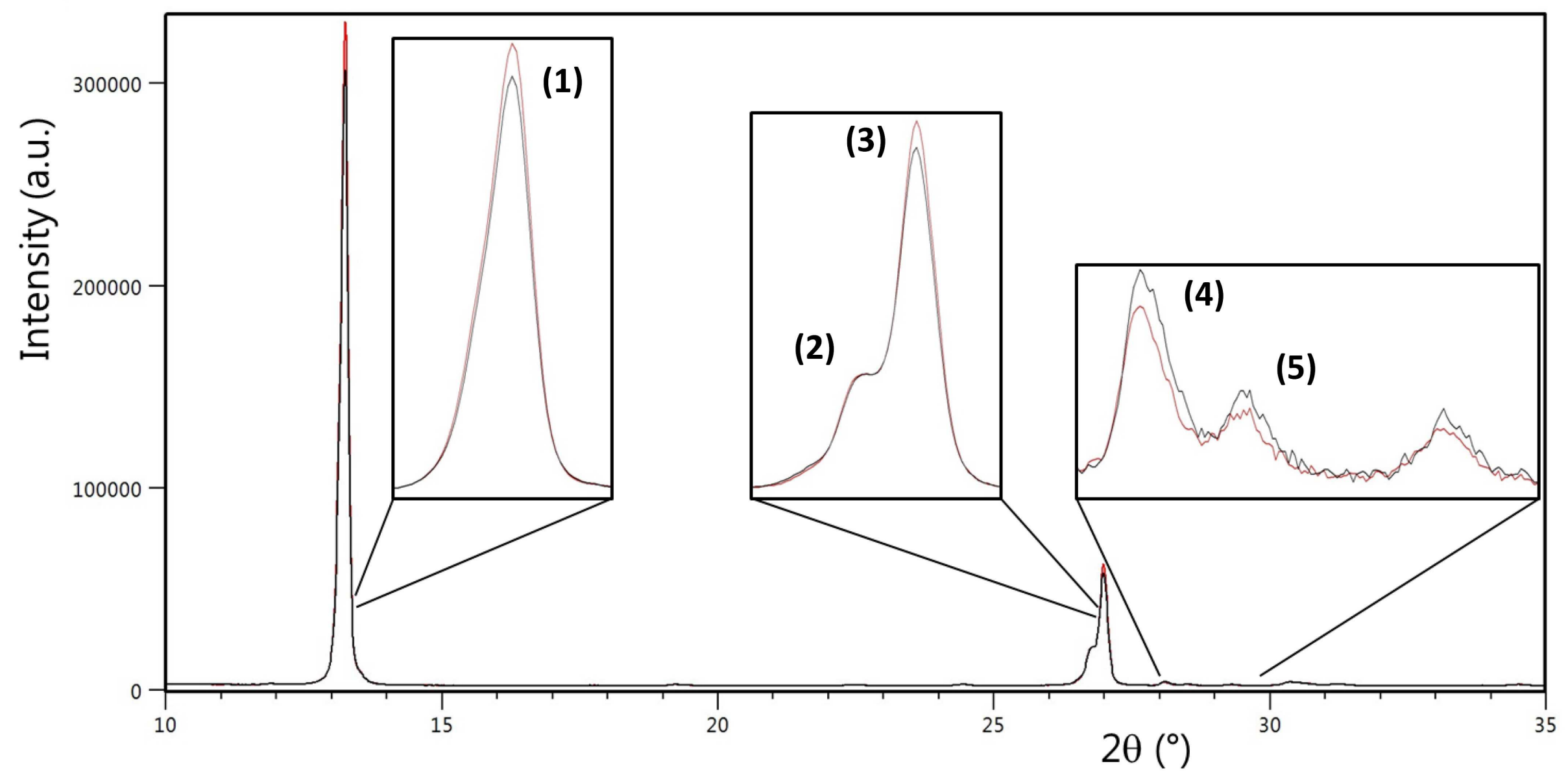


- Combination of single crystal X-Ray diffraction and ${ }^{31 P}$ MAS NMR allowed us to revisit the symmetry of $\mathrm{Li}_{1} \mathrm{VOPO}_{4} \cdot 2 \mathrm{H}_{2} \mathrm{O}$

- $\quad{ }^{7} \mathrm{Li}$ EXSY NMR combined to X-ray powder diffraction on poorly crystalline $\mathrm{Li}_{\mathrm{X}} \mathrm{VOPO}_{4} .2 \mathrm{H}_{2} \mathrm{O}(0<\mathrm{X}<1)$ evidenced a charge ordering mechanism of lithium cations between the layers taking place at timescale of at least several days.

- $\quad$ 31P NMR are showing a similar rearrangement taking place within the layers with an ordering of the $\mathrm{V}^{4+}$ versus $\mathrm{V}^{5+}$ locations. 


\section{Declaration of interests}

The authors declare that they have no known competing financial interests or personal relationships that could have appeared to influence the work reported in this paper.

ĐThe authors declare the following financial interests/personal relationships which may be considered as potential competing interests: 